\title{
CLOBAZAM KINETICS IN THE ELDERLY
}

\section{DAVID J. GREENBLATT, MARCIA DIVOLL, SURENDRA K. PURI, IRWIN HO, MIGUEL A. ZINNY \& RICHARD I. SHADER}

Division of Clinical Pharmacology. Departments of Psychiatry and Medicine, Tufts University School of Medicine and New England Medical Center Hospital, Boston; the Department of Clinical Pharmacology, Hoechst-Roussel Pharmaceuticals. Somerville. NJ: and Medical and Technical Research Associates, Boston, MA.

1 The effects of age and sex on the disposition of clobazam (CBZ), a 1,5-benzodiazepine derivative, were evaluated in a series of 29 healthy volunteers aged 18 to 72 years, who ingested single $20 \mathrm{mg}$ oral doses. CBZ kinetics were determined from multiple plasma concentrations measured during 7 days after the dose.

$2 \mathrm{CBZ}$ was rapidly absorbed, with peak levels reached an average of $1.5 \mathrm{~h}$ after dosing (range $0.5-2.5 \mathrm{~h}$ ). Mean absorption half-life was $19.7 \mathrm{~min}$. Absorption kinetics were not influenced by age or sex.

3 Elimination half-life ranged from 11 to $77 \mathrm{~h}$, and was significantly longer in elderly $v$ young males $(48 v 17 \mathrm{~h}, P<0.01)$. In women, half-life also increased with age, but differences between young and elderly women were less striking $(31 v 49 \mathrm{~h}, P<0.05)$.

4 Volume of distribution $\left(V_{d}\right)$ was influenced by age and sex. $V_{d}$ became larger with age regardless of sex, and within each age group was larger in women than in men. Total clearance was unrelated to age in women, but declined significantly with age in men $(P<0.01)$.

5 The mean free fraction for CBZ in plasma was $11.5 \%$ (range 8.6-15.0\%), and tended to increase with age, partly due to a significant age-related decline in plasma albumin concentration $(r=-0.68$, $P<0.001)$. Correction of $\mathrm{V}_{\mathrm{d}}$ and clearance for individual differences in binding did not alter their relation to age and sex.

6 As in the case of other benzodiazepines biotransformed by oxidative pathways, the capacity for $\mathrm{N}$-demethylation of CBZ declines with age in men, but age has a minimal effect on CBZ clearance in women.

\section{Introduction}

Clobazam (Figure 1) is a 1,5-benzodiazepine derivative used in the treatment of anxiety (Brogden et al., 1980; Hanks, Lader \& Lawson, 1979). Its major metabolic pathway involves hepatic $N$-demethylation, yielding a pharmacologically active metabolic product, desmethylclobazam (Figure 1). Since the ageing process may influence the pharmacokinetics of certain benzodiazepines (Greenblatt \& Shader, 1980 ), the present study was undertaken to assess the effects of age and sex on the pharmacokinetics of clobazam. a<smiles>CN1C(=O)CC(=O)N(c2ccccc2)c2cc(Cl)ccc21</smiles>

b

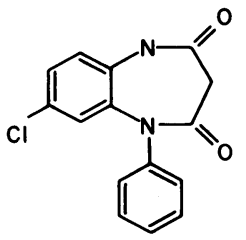

Figure 1 Structural formula of (a) clobazam and (b) its major metabolite, desmethylclobazam.

\section{Methods}

Twenty-nine healthy male and female volunteers, aged 18 to 72 years, participated after giving written informed consent. They represented four approximately equally sized groups of young male, young female, elderly male, and elderly female subjects (Table 1). All participants were active, healthy, had no evidence of medical disease, and were taking no medications on a chronic basis. Young females were not taking oral contraceptives.

After an overnight fast, subjects ingested a single 20-mg oral dose of clobazam (Hoechst-Roussel Pharmaceuticals, Somerville, NJ. USA) (two 10-mg tablets) with 100 to $200 \mathrm{ml}$ of water. They remained fasting until at least three hours after the dose. Venous blood samples were drawn by venipuncture into heparinized tubes prior to the dose and at the following post-dosage times: $0.25,0.5,0.75,1,1.5,2$, $2.5,3,4,6,8,12,24,48,72,96,120$, and $168 \mathrm{~h}$. The samples were centrifuged, and the plasma separated and frozen until the time of assay.

Concentrations of clobazam and its major meta- 
Table 1 Subject characteristics and kinetic variables for clobazam

\begin{tabular}{|c|c|c|c|c|}
\hline \multirow[b]{2}{*}{ Variables } & \multicolumn{4}{|c|}{ Mean (with range) values for: } \\
\hline & $\begin{array}{l}\text { Young male } \\
(\mathrm{n}=8)\end{array}$ & $\begin{array}{l}\text { Young female } \\
\quad(\mathrm{n}=8)\end{array}$ & $\begin{array}{l}\text { Elderly male } \\
\quad(\mathrm{n}=7)\end{array}$ & $\begin{array}{l}\text { Elderly female } \\
\quad(\mathrm{n}=6)\end{array}$ \\
\hline \multicolumn{5}{|l|}{ Subject characteristics } \\
\hline Age (years) & $\begin{array}{c}27.5^{a} \\
(20-37)\end{array}$ & $\begin{array}{c}21.3^{a} \\
(18-26)\end{array}$ & $\begin{array}{c}63.3^{a} \\
(60-69)\end{array}$ & $\begin{array}{c}64.5^{a} \\
(60-72)\end{array}$ \\
\hline Weight (kg) & $\begin{array}{c}73.0 \\
(66-80)\end{array}$ & $\begin{array}{c}59.0 \\
(48-68)\end{array}$ & $\begin{array}{c}75.0 \\
(64-82)\end{array}$ & $\begin{array}{c}63.1 \\
(57-69)\end{array}$ \\
\hline $\begin{array}{l}\text { Plasma albumin } \\
(\mathrm{g} / 100 \mathrm{ml})\end{array}$ & $\begin{array}{c}4.6^{\mathrm{a}} \\
(4.2-5.0)\end{array}$ & $\begin{array}{c}4.5^{b} \\
(4.2-4.9)\end{array}$ & $\begin{array}{c}4.1^{\mathrm{a}} \\
(3.7-4.3)\end{array}$ & $\begin{array}{c}4.3^{b} \\
(4.2-4.4)\end{array}$ \\
\hline $\begin{array}{l}\text { Smoking } \\
\quad \text { (cigarettes/day) }\end{array}$ & $\begin{array}{c}13.1 \\
(0-40)\end{array}$ & $\begin{array}{c}13.8 \\
(0-30)\end{array}$ & $\begin{array}{c}18.6 \\
(0-40)\end{array}$ & $\begin{array}{c}11.7 \\
(0-30)\end{array}$ \\
\hline \multicolumn{5}{|c|}{ Kinetics of total (free plus bound) clobazam } \\
\hline $\begin{array}{l}\text { Peak plasma concentration } \\
(\mathrm{ng} / \mathrm{ml})\end{array}$ & $\begin{array}{c}408 \\
(337-485)\end{array}$ & $\begin{array}{c}480 \\
(330-585)\end{array}$ & $\begin{array}{c}390 \\
(243-710)\end{array}$ & $\begin{array}{c}456 \\
(373-550)\end{array}$ \\
\hline $\begin{array}{l}\text { Time of peak concentration } \\
\text { (h after dose) }\end{array}$ & $\begin{array}{c}1.6 \\
(0.5-2.5)\end{array}$ & $\begin{array}{c}1.3 \\
(0.75-2.0)\end{array}$ & $\begin{array}{c}1.6 \\
(0.5-2.5)\end{array}$ & $\begin{array}{c}1.5 \\
(0.75-2.0)\end{array}$ \\
\hline $\begin{array}{l}\text { Absorption half-life } \\
(\mathrm{min})\end{array}$ & $\begin{array}{c}24 \\
(5-48)\end{array}$ & $\begin{array}{c}22 \\
(8-58)\end{array}$ & $\begin{array}{c}13 \\
(2-22)\end{array}$ & $\begin{array}{c}20 \\
(6-31)\end{array}$ \\
\hline $\begin{array}{l}\text { Elimination half-life } \\
\text { (h) }\end{array}$ & $\begin{array}{c}16.6^{\mathrm{a}} \\
(11-23)\end{array}$ & $\begin{array}{c}30.7^{b} \\
(18-46)\end{array}$ & $\begin{array}{c}47.7^{\mathrm{a}} \\
(29-77)\end{array}$ & $\begin{array}{c}48.6^{b} \\
(23-72)\end{array}$ \\
\hline $\begin{array}{l}\text { Volume of distribution } \\
(1 / \mathrm{kg})\end{array}$ & $\begin{array}{l}0.87^{\mathrm{a}} \\
(0.7-1.1)\end{array}$ & $\begin{array}{c}1.37^{\mathrm{a}} \\
(1.2-1.6)\end{array}$ & $\begin{array}{c}1.40^{\mathrm{a}} \\
(0.9-1.9)\end{array}$ & $\begin{array}{c}1.83^{\mathrm{a}} \\
(1.4-2.2)\end{array}$ \\
\hline $\begin{array}{l}\text { Total clearance } \\
\qquad\left(\mathrm{ml} \mathrm{min}^{-1} \mathrm{~kg}^{-1}\right)\end{array}$ & $\begin{array}{l}0.63^{\mathrm{a}} \\
(0.40-0.76)\end{array}$ & $\begin{array}{c}0.56 \\
(0.36-0.73)\end{array}$ & $\begin{array}{c}0.36^{\mathrm{a}} \\
(0.22-0.64)\end{array}$ & $\begin{array}{c}0.48 \\
(0.26-0.73)\end{array}$ \\
\hline \multicolumn{5}{|l|}{ Kinetics of unbound clobazam* } \\
\hline $\begin{array}{l}\text { Unbound fraction } \\
(\%)\end{array}$ & $\begin{array}{c}11.2 \\
(8.6-13.3)\end{array}$ & $\begin{array}{c}10.9 \\
(9.0-12.5)\end{array}$ & $\begin{array}{c}11.9 \\
(9.6-13.5)\end{array}$ & $\begin{array}{c}12.3 \\
(10.8-15.0)\end{array}$ \\
\hline $\begin{array}{l}\text { Unbound volume of distribution } \\
(1 / \mathrm{kg})\end{array}$ & $\begin{array}{c}8.0 \\
(5.3-10.9)\end{array}$ & $\begin{array}{c}12.6 \\
(10.7-15.4)\end{array}$ & $\begin{array}{c}12.0 \\
(6.6-19.0)\end{array}$ & $\begin{array}{c}15.1 \\
(11.3-20.5)\end{array}$ \\
\hline $\begin{array}{l}\text { Unbound clearance } \\
\qquad\left(\mathrm{ml} \mathrm{min}^{-1} \mathrm{~kg}^{-1}\right)\end{array}$ & $\begin{array}{c}5.4^{\mathrm{a}} \\
(4.0-8.6)\end{array}$ & $\begin{array}{c}5.2 \\
(3.0-7.8)\end{array}$ & $\begin{array}{c}3.1^{\mathrm{a}} \\
(1.6-5.1)\end{array}$ & $\begin{array}{c}4.3 \\
(2.3-6.7)\end{array}$ \\
\hline
\end{tabular}

${ }^{*}$ Binding data not available for 2 young males and 1 elderly female.

Significance of Student's $t$-test for difference between young and elderly of the same sex:

a: $P<0.01$

b: $P<0.05$

bolite, desmethylclobazam, were determined in all plasma samples using electron-capture gas-liquid chromatography after addition of diazepam as the internal standard (Greenblatt, 1980). In 26 of the 29 subjects sufficient plasma remained for determination of the extent of clobazam binding to plasma protein. Duplicate $2 \mathrm{ml}$ plasma samples were spiked to contain $500 \mathrm{ng} / \mathrm{ml}$ of unlabelled clobazam, together with $35 \mathrm{nCi} / \mathrm{ml}$ of $\left[{ }^{14} \mathrm{C}\right]$-clobazam $(102$ $\mu \mathrm{Ci} / \mathrm{mg}$ ). The extent of binding was determined by equilibrium dialysis as described in detail previously (Woo \& Greenblatt, 1979; Greenblatt et al., 1980).

Plasma clobazam concentrations were analyzed by iterative nonlinear least-squares regression techniques (Greenblatt et al., 1979). Data points were fitted to the following function:

$$
C=-(A+B) e^{-k a\left(t-t_{o}\right)}+A e^{-\alpha\left(t-t_{o}\right)}+B e^{-\beta\left(t-t_{o}\right)}
$$

In one subject (a young male) the fit was improved by elimination of the lag time $\left(t_{o}\right)$; in another (also a young male), an improved fit was obtained using the following function:

$$
C=B\left(e^{-\beta t}-e^{-k_{a} t}\right)
$$

In all of these functions, $C$ is the plasma concentration at time $t$ after dosing, $\mathrm{A}$ and $\mathrm{B}$ are hybrid intercept terms, and $\mathrm{k}_{\mathrm{a}}, \alpha$, and $\beta$ are hybrid exponents representing the phases of drug absorption, distribution, and elimination, respectively. $t_{o}$ is the lag time elapsing prior to the start of first-order absorption. Half-life values for absorption ( $T_{1 / 2}$ a) and elimination $T_{1 / 2} \beta$ ) were calculated as follows: 


$$
\begin{aligned}
& T_{1 / 2} \mathrm{a}=\frac{\ln 2}{\mathrm{k}_{\mathrm{a}}}=\frac{0.693}{\mathrm{k}_{\mathrm{a}}} \\
& T_{1 / 2} \beta=\frac{\ln 2}{\beta}=\frac{0.693}{\beta}
\end{aligned}
$$

The area under the plasma concentration curve from time zero to the final detectable plasma concentration as calculated using the trapezoidal method; to this was added the residual area extrapolated to 'infinity', calculated as the final plasma concentration divided by $\beta$. The sum of the these two areas represents the total area under the plasma concentration curve from time zero to infinity (AUC). Under the assumption that the entire $20 \mathrm{mg}$ dose of clobazam was available to the systemic circulation, volume of distribution using the area method $\left(V_{d}\right)$ and total clearance was calculated as follows:

$$
\text { Clearance }=\frac{\text { Dose }}{\text { AUC }} \quad \mathrm{V}_{\mathrm{d}}=\frac{\text { Clearance }}{\beta}
$$

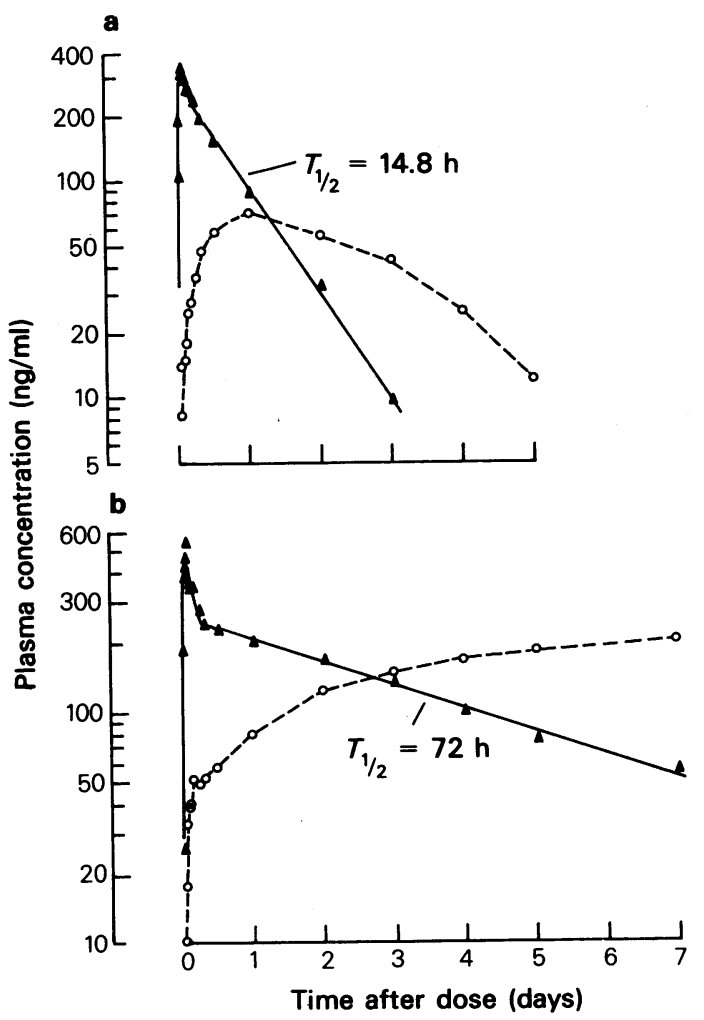

Figure 2 Clobazam ( $\boldsymbol{\Delta}$ ) and desmethylclobazam (O) concentrations following oral administration of 20 $\mathrm{mg}$ of clobazam to representative (a) young (male 27 years) and (b) elderly (female 63 years) volunteers. Solid lines are the pharmacokinetic functions for clobazam determined by nonlinear least-squares regression analysis.
For each subject, values of unbound $V_{d}$ and unbound clearance were calculated by dividing values of $V_{d}$ and clearance for total (free plus bound) clobazam by that individual's free fraction.

The effect of age and sex on kinetic variables for clobazam were analyzed using Student's $t$-test and linear regression analysis.

\section{Results}

Young and elderly subjects were comparable with respect to body weight, but plasma albumin concentrations were significantly lower in elderly as opposed to young subjects (Table 1). For all subjects, albumin concentration and age were negatively correlated $(r=-.68, P<.001)$.

Peak plasma clobazam levels averaged $434 \mathrm{ng} / \mathrm{ml}$, and were attained in an average of $1.5 \mathrm{~h}$ after the dose (Figure 2). Peak levels were lower in male as opposed to female subjects, but were not influenced by age. Time of peak concentrations was not related to either age or sex (Table 1). The mean lag time prior to the start of absorption was $14.7 \mathrm{~min}$, following which $T_{1 / 2}$ a averaged $19.7 \mathrm{~min}$. Neither lag time nor $T_{1 / 2}$ a were significantly influenced by age or sex.

Clobazam $T_{1 / 2} \beta$ increased significantly with age in men (Table 1, Figure 3). In women $T_{1 / 2} \beta$ also was prolonged in the elderly, but the age effect was less striking. Clobazam $V_{d}$ was larger in women than in men regardless of age, and was larger in the elderly as opposed to the young of both sexes (Table 1), Figure 4). Total clearance of clobazam was significantly lower in elderly as opposed to young males, but was not significantly related to age in women (Table 1 ,

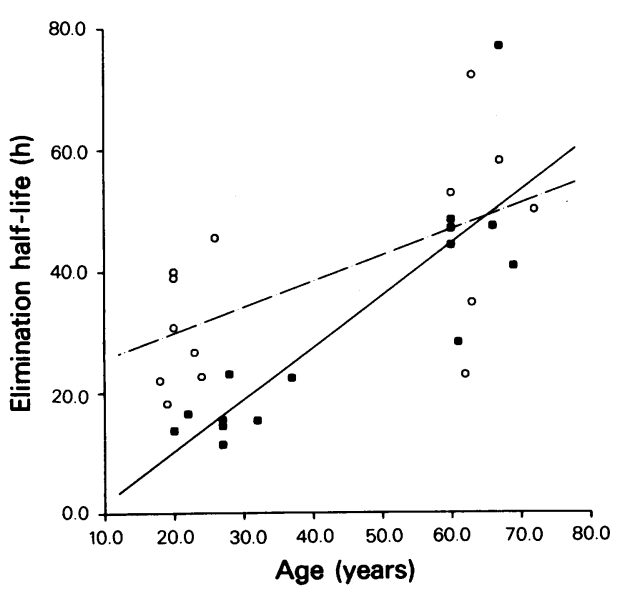

Figure 3 Relation of age to clobazam elimination halflife among men $(\square, r=0.86)$ and women $(O, r=0.60)$. Solid lines were determined by least-squares regression analysis. 


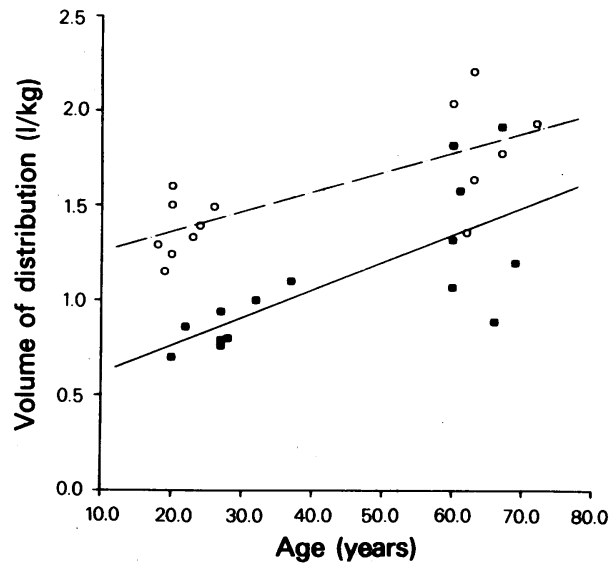

Figure 4 Relation of age to clobazam volume of distribution among men $(\square, r=0.72)$ and women $(O, r=$ $0.74)$. Solid lines were determined by least-squares regression analysis.

Figure 5). Elimination of clobazam was always mirrored by formation of its metabolite, desmethylclobazam (Figure 2). However, the duration of sampling was not sufficient to allow formal kinetic analysis of desmethylclobazam.

Clobazam was extensively bound to plasma protein. The mean free fraction was $11.5 \%$, with a range of 8.6 to $15.0 \%$. Free fraction tended to increase with age in both sexes, but the associations were not significant (Figure 6). The age-related change in free fraction was partly explained by the negative correlation of free fraction with plasma albumin concentration $(r=$ $-.39, P<.05)$, and by the decline in plasma albumin

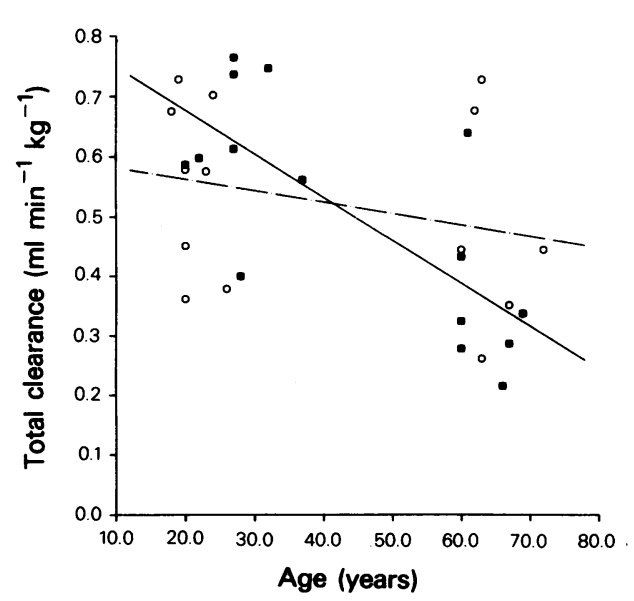

Figure 5 Relation of age to total clearance of clobazam among men $(E, r=-0.74)$ and women $(O, r=-0.27)$. Solid lines were determined by least-squares regression analysis. concentration with age. After correction for individual differences in binding, unbound $V_{d}$ was found to increase with age, although the changes did not reach significance (Table 1). As in the case of clearance of total clobazam, clearance of unbound clobazam was significantly lower in elderly as opposed to young males. In females, the relation between age and unbound clearance did not reach significance (Table 1 , Figure 7).

\section{Discussion}

The present study evaluated the effects of age and sex on the pharmacokinetics of clobazam, a 1,5-benzodiazepine antianxiety agent. In all subjects, absorption of clobazam from the gastrointestinal tract was relatively rapid. The mean time of peak concentration was $1.5 \mathrm{~h}$ after dosage, and in no case did it exceed $2.5 \mathrm{~h}$. The mean absorption half-life was 19.7 min. Peak concentrations were higher in women than in men, probably due to the smaller body weights among female subjects. Otherwise, neither age nor sex significantly influenced any of the absorption parameters.

Distribution of clobazam was influenced both by age and sex. Values of $V_{d}$ became larger with increasing age regardless of sex, and was larger in women than in men of all ages. An essentially identical relationship of $V_{d}$ to age and sex was observed in previous studies of the benzodiazepine derivatives diazepam and desmethyldiazepam (Greenblatt et al., 1980; Allen et al., 1980). These effects on drug distribution probably reflect differences in body composition. The greater proportion of total body weight com-

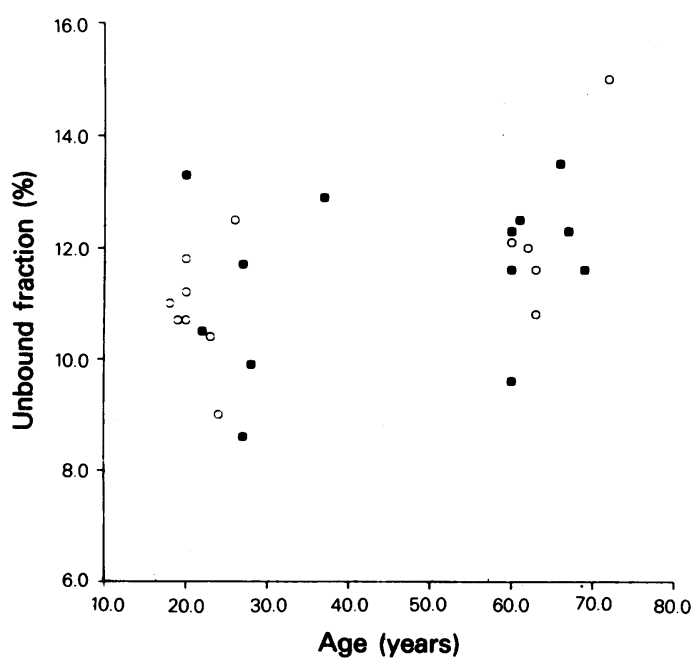

Figure 6 Relation of age to the extent of clobazam protein binding ( $\square$, male $r=0.30$, O female $r=0.57$ ). 


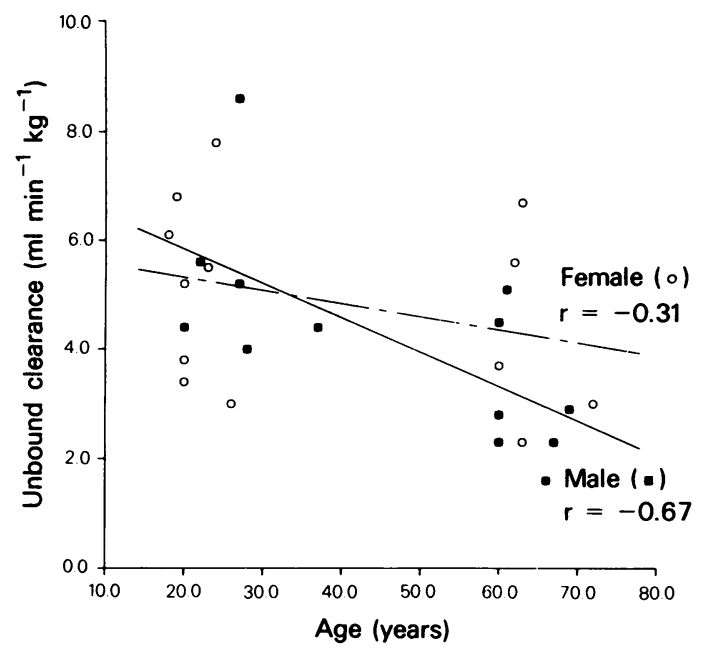

Figure 7 Relation of age to clearance of unbound clobazam. Solid lines were determined by least-squares regression analysis ( $\square$ male $r=-0.67$, O female $r=$ $-0.3(0)$.

prised of fat in women and in the elderly would lead to more extensive distribution of a lipophilic compound such as clobazam.

Both age and sex also influenced clobazam elimination and clearance. In young subjects, elimination half-life was longer in women than in men; however, this was largely due to the greater extent of distribution in women, since sex-related differences in total clearance among young subjects were minimal. Among males, half-life became significantly prolonged with age. This was not entirely explained by age-related changes in $V_{d}$, since total clearance was significantly reduced in elderly as opposed to young males. In women, however, the age-related prolongation in half-life was much less striking, and was largely attributable to the difference in $V_{d}$. Age did not significantly influence clearance among women.

Clobazam was extensively bound to plasma protein.
The mean free fraction was $11.5 \%$, with a range of 8.6 to $15.0 \%$. Free fraction tended to increase with age regardless of sex, partly due to the inverse relation of free fraction with plasma albumin concentration, together with the decline of plasma albumin in the elderly. Correction of volume and clearance terms for individual differences in binding did not alter our conclusions. Unbound $V_{d}$ for clobazam increased with age and with female sex. Furthermore, unbound clearance of clobazam declined significantly with age in men, but not in women.

The findings are highly consistent with previous studies evaluating age- and sex-related alterations in the disposition of diazepam and desmethyldiazepam (Greenblatt et al., 1980; Allen et al., 1980; Kanto et al., 1979; Klotz \& Müller-Seydlitz, 1979; Shader et al., 1981), two other lipophilic benzodiazepines biotransformed by oxidative mechanisms. In three studies from our laboratory (Greenblatt et al., 1980; Allen et al., 1980; Shader et al., 1981), the ageing process was associated with prolonged half-life and reduced clearance of both diazepam and desmethyldiazepam. However, the effects of age on the dispositional changes were far more striking in men than in women. The findings suggest that the effect of age on the capacity for oxidative biotransformation of benzodiazepines is very dependent upon sex. Our results are not likely to reflect a peculiarity of the study population, since the clobazam study and those on diazepam and desmethyldiazepam involved entirely different groups of subjects. Since both age and sex can influence the biotransformation of drugs, it is essential that studies of drug metabolism in old age be stratified for sex.

We are grateful for the assistance of Ann Locniskar, Lawrence J. Moschitto, Jerold S. Harmatz, and Dr Dean S. MacLaughlin.

This work was supported by Grant MH-34223 from the United States Public Health Service, by Grant 77-611 from the Foundations' Fund for Research in Psychiatry, and by a Grant-in-Aid from Hoechst-Roussel Pharmaceuticals, Inc.

\section{References}

ALLEN, M.D., GREENBLATT, D.J., HARMATZ, J.S. \& SHADER, R.I. (1980). Desmethyldiazepam kinetics in the elderly after oral prazepam. Clin. Pharmac. Ther., 28, 196-202.

BROGDEN. R.N.. HEEL, R.C., SPEIGHT, T.M. \& AVERY, G.S. (1980). Clobazam: a review of its pharmacological properties and therapeutic use in anxiety. Drugs, 20, 161-178.

GREENBLATT, D.J. (1980). Electron-capture GLC determination of clobazam and desmethylclobazam in plasma. J. pharm. Sci., 69, 1351-1352.
GREENBLATT, D.J., ALLEN, M.D., HARMATZ, J.S. \& SHADER, R.I. (1980). Diazepam disposition determinants. Clin. Pharmac. Ther., 27, 301-312.

GREENBLATT, D.J., ALLEN, M.D., MACLAUGHLIN, D.S., HUFFMAN, D.H.. HARMATZ, J.S. \& SHADER, R.I. (1979). Single- and multiple-dose kinetics of oral lorazepam in humans: the predictability of accumulation. $J$. Pharmacokinet. Biopharm., 7, 159-179.

GREENBLATT, D.J. \& SHADER, R.I. (1980). Effects of age and other drugs on benzodiazepine kinetics. Arzneimittel Forsch., 30, 886-890. 
HANKS, G.W., LADER, M.H. \& LAWSON, D.H. (1979). Proceedings of a symposium on clobazam. Br. J. clin. Pharmac., 7, 1S-155S.

KANTO, J., MAENPAA, M., MANTYLA, R., SELLMAN, R. \& VALOVIRTA, E. (1979). Effect of age on the pharmacokinetics of diazepam given in conjunction with spinal anesthesia. Anaesthesiol., 51, 154-159.

KLOTZ, U. \& MULLER-SEYDLITZ, P. (1979). Altered elimination of desmethyldiazepam in the elderly. Br. $J$. clin. Pharmac., 7, 119-120.
SHADER, R.I., GREENBLATT, D.J., CIRAULO, D., DIVOLL, M., HARMATZ, J.S. \& GEORGOTAS, A. (1981). Effect of age and sex on disposition of desmethyldiazepam formed from its precursor clorazepate. Psychopharmacology (in press).

WOO. E. \& GREENBLATT, D.J. (1979). Pharmacokinetic and clinical implications of quinidine protein binding. $J$. pharm. Sci., 68, 466-470.

(Received February 2, 1981) 